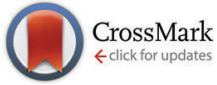

Cite this: Chem. Commun., 2016 52,8842

Received 25th April 2016, Accepted 17th June 2016

DOI: $10.1039 / c 6 c c 03452 g$

www.rsc.org/chemcomm

\section{Hydrogen bonding mediated orthogonal and reversible self-assembly of porphyrin sensitizers onto $\mathrm{TiO}_{2}$ nanoparticles $\dagger$}

\author{
Lukas Zeininger, ${ }^{a}$ Fabian Lodermeyer, ${ }^{b}$ Ruben D. Costa, ${ }^{b}$ Dirk M. Guldi*b and \\ Andreas Hirsch*a
}

\begin{abstract}
We report on the orthogonal, highly directional and reversible selfassembly of porphyrins onto $\mathrm{TiO}_{2}$ nanoparticles by means of hydrogen bonding interactions. Unifying the stable covalent surface attachment of tailored, synthesized Hamilton receptors with the advantages of a non-covalent supramolecular immobilization of porphyrin cyanurates resulted in a redox- and photo-active nanohybrid. The latter was successfully implemented into a new type of supramolecular dye-sensitized solar cells.
\end{abstract}

The controlled self-assembly of multiple components constitutes a game changing strategy to generate those collective properties that form the basis for technological applications of nanoscale devices. ${ }^{1}$ Nanohybrid materials, which are assemblies of individual particulate and molecular building blocks, feature novel specific functions such as photoinduced energy or electron transfer processes. ${ }^{2}$ Leading examples include the immobilization of sensitizers onto semiconducting metal oxide nanoparticles for photocatalytic applications, as well as dye-sensitized solar cells (DSSCs). ${ }^{3}$

In principle, many different ways enable the orthogonal grafting of redox-active components. On the one hand, covalent immobilization should be considered, which leads, for example, to the formation of self-assembled monolayers. ${ }^{4}$ On the other hand, highly directional noncovalent interactions enable the controlled and reversible formation of self-organized hybrid architectures. ${ }^{5}$ By virtue of the intrinsic tendency of inorganic nanoparticles to agglomerate - a feature that stems from their high surface area-to-volume ratio - steric and/or electrostatic stabilization by means of suitable ligands is imperative. ${ }^{6}$ As far as metal oxide nanoparticles such as titanium dioxide $\left(\mathrm{TiO}_{2}\right)$ are

\footnotetext{
${ }^{a}$ Department of Chemistry and Pharmacy, Institute of Organic Chemistry, University of Erlangen-Nürnberg, Henkestrasse 42, 91054 Erlangen, Germany. E-mail: andreas.hirsch@fau.de

${ }^{b}$ Department of Chemistry and Pharmacy \& Interdisciplinary Center for Molecular Materials, University of Erlangen-Nürnberg, Egerlandstrasse 3, 91058 Erlangen, Germany

$\dagger$ Electronic supplementary information (ESI) available: Experimental details, characterization data, and additional tables and figures. See DOI: 10.1039/ c6cc03452g
}

concerned, covalent modification can be realized by a reaction of carboxylic acids with surface bound hydroxyl groups. ${ }^{7}$ To this end, a stable attachment of suitable self-assembled monolayers providing both colloidal stability and an access to the noncovalent attachment of organic functionalities via self-organization facilitates the creation of organic-inorganic hybrid structures. ${ }^{8}$ In such systems, unique advantages of a covalent and non-covalent surface modification can be combined.

Interactions on the supramolecular level are susceptible to exterior factors such as the solvent or $\mathrm{pH}$, which affect the association constants and, in turn, allow the precise control over reversibility. ${ }^{9}$ Hydrogen bonding complexes are of great interest due to their reversibility. For example, a strong solvent dependence with the formation of stable complexes only in apolar solvents enables altering the binding as a function of environments. ${ }^{10}$ A leading example of a hydrogen bonding motif is the Hamilton receptor with its six-point hydrogen bonding interactions. It binds easily and strongly cyanurates with association constants of $10^{3}$ to $10^{6} \mathrm{M}^{-1}$ in apolar solvents as a reflection of a high degree of specificity, rigidity and directionality. ${ }^{11}$ Notable is the fact that this motif has been utilized en route towards a myriad of supramolecular architectures with some of them revealing charge transfer activity. ${ }^{12}$ Grafting of Hamilton receptors onto inorganic nanoparticles in order to generate functional organic-inorganic hybrid structures has, however, never been reported so far.

Herein, we report on a novel supramolecular strategy for the noncovalent grafting of porphyrins onto the surface of $\mathrm{TiO}_{2}$ nanoparticles - Scheme 1. For the first time, a reversible, orthogonal surface modification of $\mathrm{TiO}_{2}$ nanoparticles was realized by hydrogen bonding interactions of tailor synthesized, surface immobilized Hamilton receptors (1) with porphyrin cyanurates (2). Moreover, the resulting nanohybrids - $\mathbf{T i O}_{\mathbf{2}} \mathbf{- 1} \cdot \mathbf{2}$ exhibited increased particle stability and were isolated as stable solids. In addition, $\mathbf{T i O}_{2}-\mathbf{1} \cdot \mathbf{2}$ were successfully implemented as active layers in a novel type of DSSCs.

Initially, a suitable anchor for the binding to $\mathrm{TiO}_{2}$ surfaces was added to the Hamilton receptor. To this end, a hitherto 


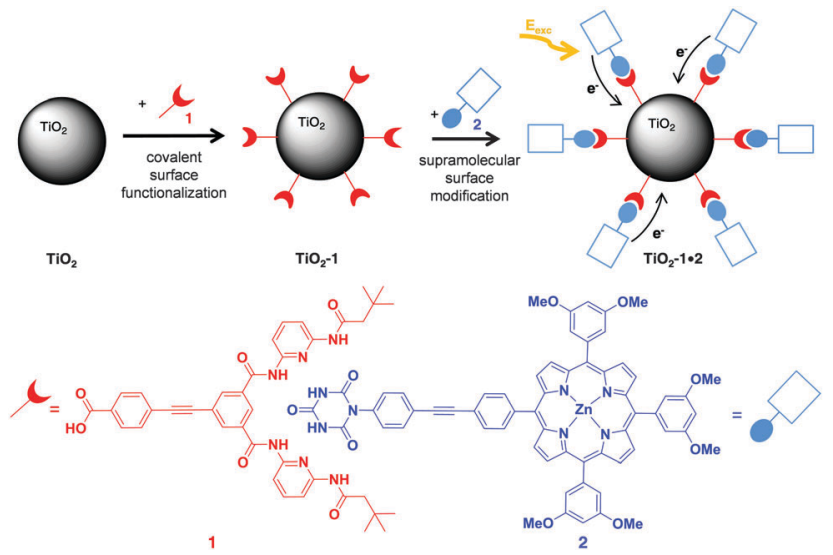

Scheme 1 Conceptional sketch of the supramolecular self-assembly of porphyrins onto $\mathrm{TiO}_{2}$ nanoparticles by means of hydrogen bonding interactions.

unknown Hamilton receptor 1, covalently endowed with a carboxylic acid anchor group, was synthesized - Scheme 2 . The Hamilton receptor 1 was synthesized by coupling iodoHamilton receptor 3 and tert-butyl 4-ethynylbenzoate 4 in a Sonogashira-type reaction. Deprotection of the obtained ester yielded the carboxylic acid Hamilton receptor 1, which was characterized by NMR and HR-MS techniques (see the, ESI $\dagger$ ), in quantitative yields. The rigid spacer was chosen to ensure orthogonal attachment relative to the surface, which is important to control charge transfer processes. For the same reason, the cyanurate moiety was linked to porphyrin 2 via a rigid phenylene-ethynylene spacer. Porphyrin $\mathbf{2}$ was synthesized and characterized according to a previously reported procedure. ${ }^{13}$

${ }^{1} \mathrm{H}-\mathrm{NMR}$ titration experiments were carried out to determine the association constant of porphyrin cyanurate 2 with Hamilton receptor 5 - Fig. 1. In this measurement, 5 was employed to avoid any competing hydrogen bonding interactions of the free carboxylic acid with the Hamilton receptor. By plotting the chemical shift of the amide protons $\mathrm{NH} 1$ and NH2 of 5 versus the added equivalents of porphyrin cyanurate 2 the association constant was calculated to be $4.8 \times 10^{3} \mathrm{M}^{-1}$ using the software HypNMR 2008 (version 4.0.68; Protonic software; Leeds; UK). In addition, a Job's plot analysis of the titration data was carried out. Well in line with the expectation, our findings corroborated a stoichiometry of $1: 1$ of the formed supramolecular complex (see the ESI $\dagger$ ). For further characterization emission spectra were also recorded (see the ESI $\dagger$ ). A hypsochromic shift of the emission of the Hamilton receptor 5 from 528 to $509 \mathrm{~nm}$ was observed upon formation of the hydrogen

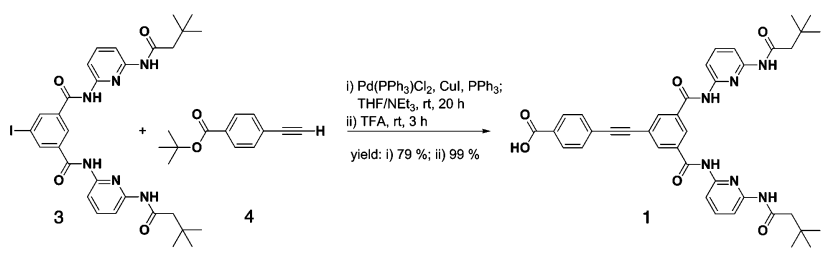

Scheme 2 Synthesis of carboxylic acid-Hamilton receptor 1.

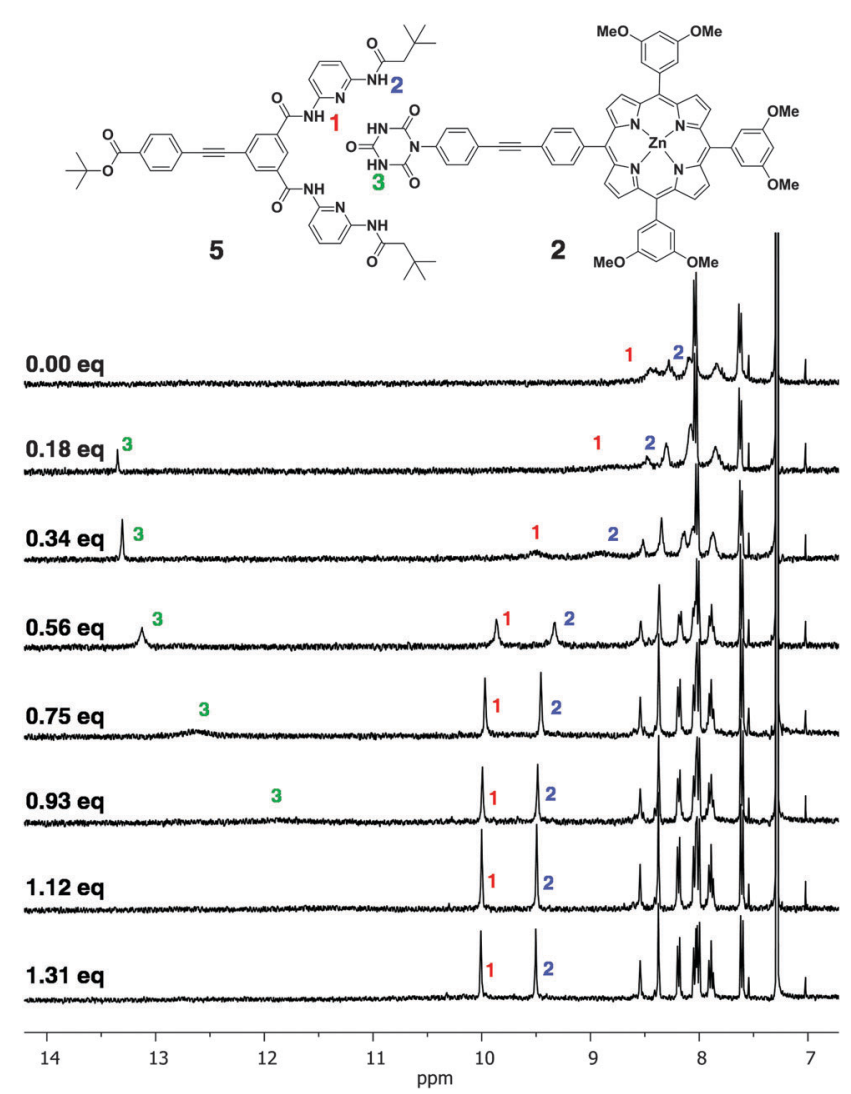

Fig. $1{ }^{1} \mathrm{H}-\mathrm{NMR}$ titration of Hamilton receptor $\mathbf{5}$ with equivalents of porphyrin cyanurate $2\left(\mathrm{CDCl}_{3} ; \mathrm{rt} ; 400 \mathrm{MHz}\right)$.

complex. Such a shift indicates electronic communication between the two constituents in the supramolecular complex, an effect, which has been observed previously. ${ }^{14}$

Next, the binding scheme was transferred to the surface of nanoparticles. We opted for commercially available nanograde ${ }^{\circledR} \mathrm{TiO}_{2}$ anatase nanoparticles with a specific surface area of $46 \mathrm{~m}^{2} \mathrm{~g}^{-1}$ and an average diameter of $34 \mathrm{~nm}$, as determined in BET measurements (see the ESI $\dagger$ ). Chemical functionalization of $\mathrm{TiO}_{2}$ nanoparticles was accomplished by means of a wet-synthetic procedure. In a typical experiment, $\mathrm{TiO}_{2}$ nanoparticles were functionalized in $0.15 \mathrm{wt} \%$ dispersions in isopropanol. The nanoparticles were functionalized with Hamilton receptor $\mathbf{1}$ to yield $\mathbf{T i O}_{2}-\mathbf{1}$. To determine the conditions for a complete monolayer surface coverage the particles were exposed to different concentrations of Hamilton receptor 1. The corresponding grafting densities were calculated from the weight loss in TGA measurements. ${ }^{15}$ The latter were plotted versus the concentration of Hamilton receptor 1, resulting in a typical Langmuir isotherm for monolayer adsorption (see the $\mathrm{ESI} \dagger$ ). Employing the Langmuir formula the maximum monolayer grafting density for the functionalization of these $\mathrm{TiO}_{2}$ nanoparticles in this specific equilibrium of solvent and ligands was determined (see the ESI $\dagger$ ). As a result, monolayer functionalized nanoparticles $\mathbf{T i O}_{\mathbf{2}} \mathbf{- 1}$ featured a maximum monolayer grafting density of 1.4 molecules per $\mathrm{nm}^{2}$. Such systematic binding experiments further revealed that applying concentrations for $\mathbf{1}$ 


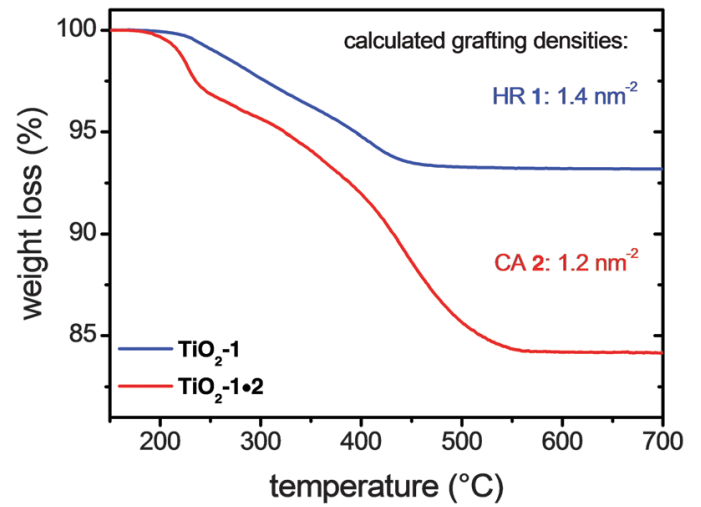

Fig. 2 TGA weight loss curves of $\mathrm{TiO}_{2}-\mathbf{1}$ and $\mathrm{TiO}_{2}-\mathbf{1} \cdot \mathbf{2}$ together with the corresponding grafting densities of Hamilton receptor 1 and porphyrin 2 (TGA measured under $\mathrm{O}_{2} / \mathrm{N}_{2} 10 \mathrm{~mL}: 40 \mathrm{~mL}$ and a heat rate of $10 \mathrm{~K} \mathrm{~min}^{-1}$, approx. sample weight: $10 \mathrm{mg}$ ).

of $5 \mathrm{mM}$ and higher led to a complete monolayer coverage. A typical TGA measurement of a dried powder $\left(80^{\circ} \mathrm{C}\right)$ of coated nanoparticles $\mathbf{T i O}_{\mathbf{2}} \mathbf{- 1}$, which were functionalized with $5 \mathrm{mM}$ of 1 is depicted in Fig. 2. Sterically stabilized 1st shell coated $\mathbf{T i O}_{2}-1$ were stable against aggregation and growth, were easily re-dispersible even after drying at $80{ }^{\circ} \mathrm{C}$, and were accessible for further surface modification. Next, complexation of porphyrin cyanurate 2 to afford the final $\mathbf{T i O}_{2}-\mathbf{1} \cdot \mathbf{2}$ nanohybrid was carried out by re-dispersing the functionalized nanoparticles $\mathbf{T i O}_{\mathbf{2}} \mathbf{- 1}$ in chloroform and the subsequent addition of porphyrin cyanurate 2 .

As previously shown, ${ }^{16}$ the hydrogen bonding mediated attachment of porphyrin cyanurate 2 to $\mathbf{T i O}_{2}-\mathbf{1}$ was accomplished by addition of a $0.5 \mathrm{mM}$ chloroform solution of 2 to $\mathbf{T i O}_{2}-\mathbf{1}$ yielding a purple hybrid material $\mathbf{T i O}_{2} \mathbf{- 1} \cdot \mathbf{2}$ after centrifugation. From a typical TGA measurement with the final nanohybrid a grafting density of 1.2 porphyrins per $\mathrm{nm}^{2}$ was concluded. Such a value correlates with 85\% of the surface-bound Hamilton receptors that associate with 2. $\mathbf{T i O}_{2}-\mathbf{1} \cdot \mathbf{2}$ nanoparticles were easily re-dispersible in chloroform. After addition of polar solvents like isopropanol, the porphyrin cyanurate 2 was, however, found in the supernatant, while the precipitate consisted of colorless particles $\mathbf{T i O}_{2} \mathbf{- 1}$ again. A TGA taken for this precipitate was almost identical to that of pure $\mathbf{T i O}_{2}-\mathbf{1}$.

The reversibility of the porphyrin cyanurate 2 binding to $\mathbf{T i O}_{2} \mathbf{- 1}$ was nicely reflected in time-dependent absorption studies as depicted in Fig. 3. Here, the porphyrin cyanurate 2 was adsorbed on a $\mathrm{TiO}_{2}$ coated glass slide, which was covalently surface modified with Hamilton receptor 1 . The adsorption and desorption upon immersing the glass slide in porphyrin solutions, pure chloroform, isopropanol, and a solution of a competing cyanurate was tracked in time-dependent absorption measurements. The transparent nanocrystalline $\mathrm{TiO}_{2}$ layer (Ti-nanoxide T/SP, Solaronix; thickness: $7 \mu \mathrm{m}$ ) was prepared on an untreated glass slide by using a doctor blade technique. First, the glass slide was exposed to Hamilton receptor $\mathbf{1}$ in isopropanol ( $0.5 \mathrm{mM}$ ) for $24 \mathrm{~h}$ for complete monolayer coverage of the $\mathrm{TiO}_{2}$ nanoparticles. After washing, the glass slide was immersed in a chloroform solution of porphyrin cyanurates 2 (0.5 mM). In Fig. 3, the absorption of the porphyrin Q-band at

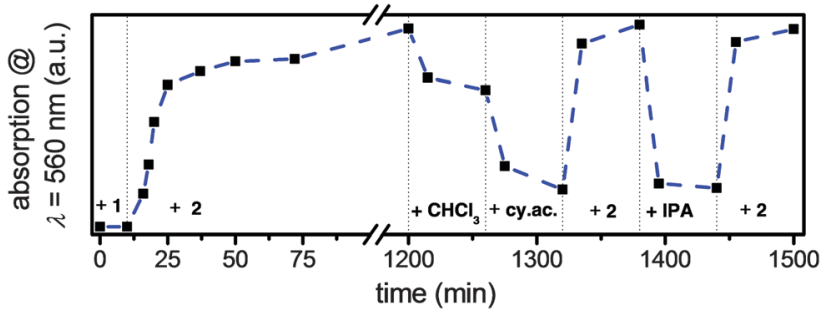

Fig. 3 Time-dependent UV-Vis study for an illustration of the reversibility of the self-assembly of porphyrin 2 on Hamilton receptor modified $\mathrm{TiO}_{2}$ layers (absorption at $\lambda=560 \mathrm{~nm}$ vs. time).

$\lambda=560 \mathrm{~nm}$ is shown as a function of time. The immersion of the coated glass slide in the porphyrin cyanurate 2 chloroform solution evoked an increase of the absorption intensity. In reference experiments, $\mathrm{TiO}_{2}$ glass slides were exposed to pure porphyrin cyanurate 2 without prior surface modification with 1 . Here, the porphyrin absorption was less than $0.05 \%$ of the preHamilton receptor functionalized glass slides. From the latter, we conclude the successful surface attachment. Next, the impact of the hydrogen bonding mediated surface adsorption was investigated. In this context, the modified $\mathrm{TiO}_{2}$ glass slide $\mathbf{T i O}_{2} \mathbf{- 1} \cdot \mathbf{2}$ - was immersed in chloroform. Only a slight decrease was noted. In the presence of tert-butyl 8-(cyanurato)octanoate ${ }^{17}$ (cy.ac.) a replacement of porphyrin cyanurate 2 initiated a decrease of porphyrin absorption on the glass slide. Vice versa, immersing the latter slides in a porphyrin cyanurate 2 chloroform solution resulted in re-increase of the porphyrin absorption. Similarly, addition of isopropanol (IPA) as a means to interfere with the hydrogen bonding led to the reversible decrease of the porphyrin absorption.

Finally, we implemented this novel binding scheme into light-harvesting devices based on the DSSC concept. In brief, upon photo-excitation, the porphyrin 2 injects an electron into the conduction band of $\mathrm{TiO}_{2}$. While the latter performs external work, the electrolyte $\left(\Gamma / I^{3-}\right.$ redox couple) regenerates porphyrin 2. Finally, the electrolyte is also regenerated at the counter electrode interface. Herein, the photovoltaic characteristics were evaluated using a typical sandwich-type DSSC configuration, which comprised a $7 \mu$ m-thick layer of $\mathbf{T i O}_{2}$-based photoanode and a platinum counter electrode (see the $\mathrm{ESI} \dagger$ for more details). The $\mathrm{TiO}_{2}$ electrode was placed into an isopropanol solution of $\mathbf{1}$ $(0.5 \mathrm{mM})$ for $24 \mathrm{~h}$ to allow full coverage of the mesoporous network and it was subsequently sensitized in chloroform with porphyrin cyanurate $2(0.5 \mathrm{mM})$ for $24 \mathrm{~h}$. Fig. 4 shows the current-voltage $(J-V)$ characteristics measured under 1 sun $\left(100 \mathrm{~mW} \mathrm{~cm}^{-2}\right)$ simulated AM 1.5G solar illumination (see the ESI $\dagger$ ). The aforementioned configuration resulted in an open-circuit voltage $\left(V_{\mathrm{OC}}\right)$ of $0.50 \mathrm{~V}$, a short-circuit current density $\left(J_{\mathrm{SC}}\right)$ of $0.18 \mathrm{~mA} \mathrm{~cm}^{-2}$, a fill factor (FF) of 0.62 , and an efficiency $(\eta)$ of $0.06 \%$. As a reference experiment, devices with $\mathbf{T i O}_{2} \mathbf{- 1}$ and $\mathbf{T i O}_{2}-2$ were analyzed. Here, the FF and $V_{\mathrm{OC}}$ are similar to those seen for $\mathbf{T i O}_{2} \mathbf{- 1} \cdot \mathbf{2}$ devices, while their $J_{\mathrm{SC}}$ is reduced to about half of that noted for $\mathbf{T i O}_{\mathbf{2}} \mathbf{- 1} \cdot \mathbf{2}$.

To further corroborate this notion, incident photon-tocurrent efficiency (IPCE) assays of DSSCs with and without 


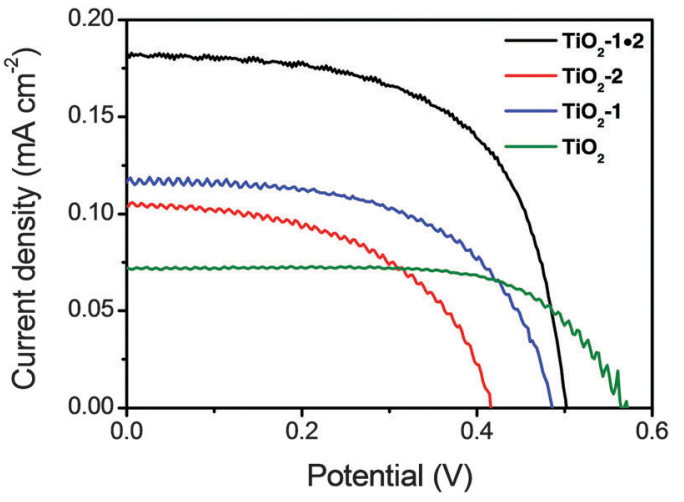

Fig. $4 \mathrm{~J}-\mathrm{V}$ curves of devices with $\mathrm{TiO}_{\mathbf{2}}-\mathbf{- 1}, \mathrm{TiO}_{\mathbf{2}}-\mathbf{2}, \mathrm{TiO}_{\mathbf{2}}-\mathbf{- 1} \cdot \mathbf{2}$, and bare $\mathrm{TiO}_{2}$ under 1 sun illumination in AM 1.5 conditions.

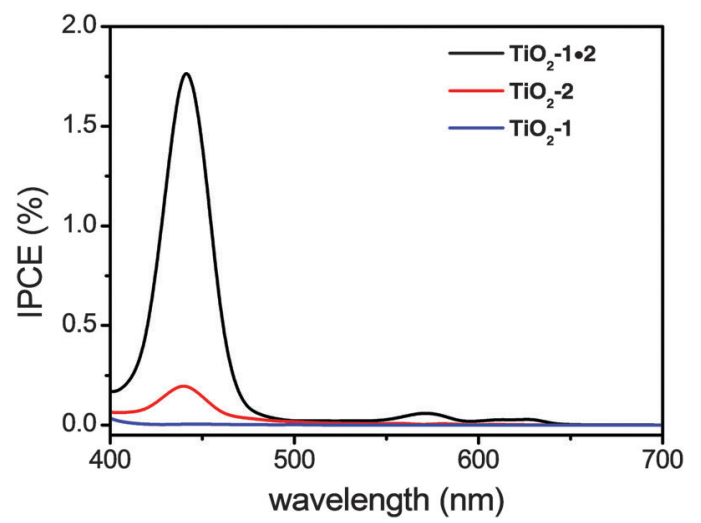

Fig. 5 IPCE spectra of devices with $\mathrm{TiO}_{2}-\mathbf{1}, \mathrm{TiO}_{2}-\mathbf{2}$, and $\mathrm{TiO}_{2}-\mathbf{1} \cdot \mathbf{2}$.

immobilization of Hamilton receptor $\mathbf{1}$ and subsequent uptake of porphyrin cyanurate 2 were performed.

Here, sufficient electron injection from porphyrin 2 to $\mathrm{TiO}_{2}$ mediated by the Hamilton receptor 1 was noted with Soret- and Q-band contributions at 440 and $560 / 610 \mathrm{~nm}$, respectively. In stark contrast, no appreciable electron injection from the porphyrin to $\mathrm{TiO}_{2}$ was derived from the IPCE spectrum, when $\mathrm{TiO}_{2}$ was sensitized only with porphyrin cyanurate 2 without prior surface immobilization of 1 (Fig. 5). As such, the photocurrent in the current density versus voltage $(J-V)$ characteristics stemmed mainly from $\mathrm{TiO}_{2}$. As a matter of fact, we confirmed that upon porphyrin excitation the electron transfer was mediated by the Hamilton receptor-cyanurate hydrogen bonding motif towards the $\mathrm{TiO}_{2}$ electrode. Our studies constitute the first representative of a sensitizer orthogonally attached to a $\mathrm{TiO}_{2}$ active layer via a highly directional and specific hydrogen bonding complex.

To conclude, we presented a novel approach for an orthogonal, non-covalent immobilization of porphyrins onto $\mathrm{TiO}_{2}$ nanoparticles. Key is a Hamilton receptor cyanurate hydrogen bonding complex. To this end, a redox- and photo-active organic-inorganic hybrid system was created, in which the advantages of a covalent surface modification - stability; densely packed monolayers - were combined with the assets of supramolecular chemistry - reversibility; directionality. This work further paves the way towards gaining control over replacing chromophores in operating devices and a tailored mixed-assembly of multiple sensitizers on semiconducting metal oxide surfaces.

Financial support from the Cluster of Excellence "Engineering of Advanced Materials" (EAM), funded by the German Research Council (DFG), and the Graduate Schools "Advanced Materials and Processes" (GSAMP) and "Molecular Science" (GSMS) is gratefully acknowledged.

\section{Notes and references}

1 (a) A. B. Descalzo, R. Martínez-Máñez, F. Sancenon, K. Hoffmann and K. Rurack, Angew. Chem., Int. Ed., 2006, 45, 5924-5948; (b) A. K. Boal, F. Ilhan, J. E. DeRouchey, T. Thurn-Albrecht, T. P. Russell and V. M. Rotello, Nature, 2000, 404, 746-748.

2 (a) D. Michael, Chem. Soc. Rev., 1997, 26, 365-375; (b) P. V. Kamat, J. Phys. Chem. C, 2007, 111, 2834-2860.

3 (a) B. O'Regan and M. Grätzel, Nature, 1991, 353, 737-740; (b) S. Mathew, A. Yella, P. Gao, R. Humphry-Baker, B. F. Curchod, N. Ashari-Astani, I. Tavernelli, U. Rothlisberger, M. K. Nazeeruddin and M. Grätzel, Nat. Chem., 2014, 6, 242-247; (c) J. Schneider, M. Matsuoka, M. Takeuchi, J. Zhang, Y. Horiuchi, M. Anpo and D. W. Bahnemann, Chem. Rev., 2014, 114, 9919-9986.

4 (a) A. Ulman, Chem. Rev., 1996, 96, 1533-1554; (b) L. Zhang and J. M. Cole, ACS Appl. Mater. Interfaces, 2015, 7, 3427-3455.

5 R. Shenhar and V. Rotello, Acc. Chem. Res., 2003, 36, 549-561.

6 D. Segets, R. Marczak, S. Schäfer, C. Paula, J.-F. Gnichwitz, A. Hirsch and W. Peukert, ACS Nano, 2011, 5, 4658-4669.

7 (a) S. P. Pujari, L. Scheres, A. T. M. Marcelis and H. Zuilhof, Angew. Chem., Int. Ed., 2014, 53, 6322-6356; (b) Y. Bai, I. Mora-Seró, F. D. Angelis, J. Bisquert and P. Wang, Chem. Rev., 2014, 114, 10095-10130.

8 (a) J.-F. Gnichwitz, R. Marczak, F. Werner, N. Lang, N. Jux, D. M. Guldi, W. Peukert and A. Hirsch, J. Am. Chem. Soc., 2010, 132, 17910-17920; (b) L. Zeininger, S. Petzi, J. Schönamsgruber, L. Portilla, M. Halik and A. Hirsch, Chem. - Eur. J., 2015, 21, 14030-14035.

9 J.-M. Lehn, Science, 2002, 295, 2400-2403.

10 S. Mann, W. Shenton, M. Li, S. Connolly and D. Fitzmaurice, Adv. Mater., 2000, 12, 147-150.

11 (a) S.-K. Chang and A. D. Hamilton, J. Am. Chem. Soc., 1988, 110, 1318-1319; (b) C. Dethlefs, J. Eckelmann, H. Kobarg, T. Weyrich, S. Brammer, C. Näther and U. Lüning, Eur. J. Org. Chem., 2011, 2066-2074.

12 (a) A. Dirksen, U. Hahn, F. Schwanke, M. Nieger, J. N. H. Reek, F. Vögtle and L. de Cola, Chem. - Eur. J., 2004, 10, 2036-2047; (b) F. Wessendorf, J.-F. Gnichwitz, G. H. Sarova, K. Hager, U. Hartnagel, D. M. Guldi and A. Hirsch, J. Am. Chem. Soc., 2007, 129, 16057-16071; (c) R. Zirbs, F. Kienberger, P. Hinterdorfer and W. H. Binder, Langmuir, 2005, 21, 8414-8421; (d) G. Schaeffler, O. Fuhr, D. Fenske and J.-M. Lehn, Chem. - Eur. J., 2014, 20, 179-186.

13 F. Wessendorf and A. Hirsch, Tetrahedron, 2008, 64, 11480-11489.

14 P. Tecilla, R. P. Dixon, G. Slobodkin, D. S. Alavi, D. H. Waldeck and A. D. Hamilton, J. Am. Chem. Soc., 1990, 112, 9408-9410.

15 L. Portilla and M. Halik, ACS Appl. Mater. Interfaces, 2014, 6, 5977-5982.

16 L. Zeininger, M. Klaumünzer, W. Peukert and A. Hirsch, Int. J. Mol. Sci., 2015, 16, 8186-8200.

17 S. Bosch, L. Zeininger, F. Hauke and A. Hirsch, Chem. - Eur. J., 2014, 20, 2537-2541. 